\title{
The Relationship between Nordic Hamstring Test and Isokinetic Dynamometry in Football and Track and Field Student Athletes: a Cross-Sectional Study
}

\author{
N. Sadri-Aghdam ${ }^{1}$, M. Rezaei ${ }^{1}$, M. R. Azghani ${ }^{2}$, F. Ghaderi ${ }^{1}$, H. Adigozali ${ }^{1}$ \\ 1 Department of Physiotherapy, Faculty of Rehabilitation Sciences, Tabriz University of Medical Sciences, \\ Tabriz, Iran \\ 2 Department of Biomechanics, Faculty of Biomechanics Engineering, Sahand University of Technology, \\ Tabriz, Iran
}

\section{CORRESPONDING AUTHOR: \\ Mandana Rezaei \\ Physiotherapy Department \\ Faculty of Rehabilitation Sciences \\ Tabriz University of Medical Sciences \\ University Street \\ Tabriz, Iran \\ E-mail: rezaeiman@tbzmed.ac.ir}

DOI:

10.32098/mltj.04.2020.24

LEVEL OF EVIDENCE: 3B

\begin{abstract}
SUMMARY
Background. Nordic hamstring test is a field-based test to estimate the hamstrings' injury risk. The aim of this study was to investigate the relationship between Nordic hamstring test and isokinetic dynamometry in football and track and field student athletes.

Methods. Knee flexor eccentric peak torque of hamstring, optimum length, and muscle balance indices were obtained in two seated and lying positions in 22 footballs and 22 track and field student athletes. The Nordic break point angle was also measured.

Results. There were significant correlations between isokinetic dynamometry indices and breakpoint angles $(\mathrm{P}=0.000)$. Best predictors of break point angle were muscle balance indices and eccentric hamstring peak torques in lying position $(\mathrm{P}<0.05)$.

Conclusions. It seems that Nordic hamstring test is related to isokinetic dynamometry. This relationship is also dependent on the hip joint positioning. These findings may have implications in the assessment of athletic performance.
\end{abstract}

\section{KEY WORDS}

Hamstring muscles performance; atbletic; muscle strength; track and field; football.

\section{BACKGROUND}

Hamstring strain (HS) is one of the most prevalent injuries in sprint-related sports like football, rugby and track and field that cause high financial costs for teams and athletes (1). In Australian football league, the cost of HS increased to 40021 AUD for every single injury in 2012 (1). The Injury rate is between $6-29 \%$ in different sports (2). In football, $8 \%-25 \%$ of all injuries and $26 \%$ of all injuries in track and field athletes are related to the HS (3). Overstretch and explosive eccentric contractions are two main mechanisms for HS occurrence (2).

Isokinetic dynamometry is commonly used as a golden standard to assess the hamstring eccentric ability (4). The hamstring eccentric ability is one of the most important dynamometry indices to estimate the risk of HS; that means decreased eccentric hamstring muscle strength can lead to injury (4-7). Another index is reciprocal knee joint muscle balance that is commonly expressed as hamstring to quadri- ceps muscle ratios (H/Q ratios) $(4,8) . \mathrm{H} / \mathrm{Q}$ ratios including hamstring Concentric $_{\text {to }}$ Quadriceps ${ }_{\text {Concentric }}$ ratio and hamstring to Quadriceps Concentric ratio (4). Previous studies have shown that a decrease in $\mathrm{H} / \mathrm{Q}$ ratios will increase the risk of HS among athletes $(4,9,10)$. On the other hand, some authors claimed that these ratios cannot predict the injury occurrence (11). Therefore, recently a new muscle balance index is introduced as the angle of crossover (ACO). ACO represents the angle at which the net joint torque around the knee joint crosses zero (12). It reveals hamstring capability to eccentrically overcome the quadriceps concentric action (12). ACO is proposed to be a better index than H/Q ratios to estimate the HS risk (12). Shortened hamstring optimum length (OL) is considered as another HS risk factor (13). $\mathrm{OL}$ is the length that muscle demonstrates peak torque (14). Shorter the OL shifts, more susceptibility to the HS (15). Overall, isokinetic dynamometry needs technical expertise and is difficultly accessible in athletic centers because 
of high cost and time consumption (16). In addition, the occurrence of exercise-induced muscle soreness after isokinetic dynamometry is high (17). Ultimately, dynamometry procedure cannot be applicable on athletic field. Therefore, developing field based tests with low cost and easy access seems to be necessary.

Nordic hamstring exercise was introduced in 2001 as a hamstring eccentric strengthening exercise (18). It is shown that Nordic hamstring exercise can improve eccentric strength of hamstrings and probably decrease the rate and recurrence of HS in athletes $(19,20)$. Recently, some authors claimed that this exercise defined as Nordic hamstring test (NHT) can also be used as a field test for assessing the hamstring eccentric capability $(17,21,22)$. Breakpoint angle (BPA) is defined as an angle that an individual cannot overcome increasing gravitational moment and falls to the floor when performing NHT. BPA is considered as an outcome measure for the athletic performance (21). Correlations between BPA and peak torques of hamstrings were demonstrated in football players $(17,21,22)$. As said before, HS is also prevalent in track and field $(3,23)$. The applicability of NHT as a field test in track and field has not known yet. These relationships between NHT and isokinetic dynamometry were explored in the seated position only (17, 21, 22). Whereas, the athletic performances are commonly carried out in standing position, and the amount of knee joint torques depends on the change in the hip and knee joint positions $(24,25)$. Hence, the position of the hip joint should be considered when evaluating the relationship between NHT and isokinetic dynamometry. Therefore, the purpose of this study was to investigate the relationships between NHT as a field test and isokinetic dynamometry as a gold standard laboratory test (dynamometry indices including eccentric hamstring peak torques, H/Q ratios, $\mathrm{ACO}$, and $\mathrm{OL}$ ) performed in seated and lying positions in two groups of football and track and field athletes.

\section{MATERIALS AND METHODS}

\section{Study design}

A cross sectional study was designed to determine the relationship between Nordic hamstring test and isokinetic dynamometry in two groups of football and track and field athletes.

\section{Participants}

Forty four healthy male student athletes (26) were purposefully divided into two groups including 22 football players and 22 track and field athletes. Convenient sample from the available student athletes were participated voluntarily in both groups and were matched based on the demographic variables mentioned above. Participants included based on performing specific sport drills as the training programs designed by university coaches and received scheduled training programs on the weekly basis in university teams. They aged between 18 to 24 years and were classified as physically active based on the Tegner physical activity questionnaire (gained score 6 or more on the questionnaire). Participants with the history of hamstring strain and/or other lower limb problems like fractures and soft tissue injuries at last 6 months ago, presences of hyper lordosis in the lumbar spine (evaluated by an experienced physiotherapist as postural screening), and the history of epilepsy or other neurologic disorders were excluded. Another physiotherapist conducted the remained procedure including dynamometry and NHT. The sample size was calculated based on the expected correlation coefficient reported in the study of sconce (21). The total number of participants in each group was equal to 22 persons.

The present study was approved by the ... ethical committee (...1396.979) and signed informed consent was obtained from each participant. Also, participants have given written informed consent to publish these case details. The study meets the ethical standards of the journal (27). This study was conducted in Biomechanics laboratory of ... since 2016 to 2018.

\section{Experimental procedures}

After familiarization with the procedure, each subject filled the basic information form. Subjects were asked to avoid eating and performing high intensity training exercises two and 48 hours before the tests respectively. Warm up including lower extremity stretching exercises and walking for three minutes was performed at first. Then, isokinetic dynamometry and Nordic hamstring tests were done.

\section{Isokinetic dynamometry}

Participants were familiarized with Cybex HUMAC NORM Isokinetic Extremity System [CSMI, Stoughton, MA] through performing four sub-maximal contractions. The dominant leg was tested in all subjects. Each subject was examined in two seated and lying positions using dynamometer to extract hamstring and quadriceps eccentric and concentric peak torques at the constant velocity $60^{\circ} / \mathrm{s}(21)$. In each position, subject's trunk and thighs were fixed with straps to avoid extra and uncontrolled movements and axis of rotation of the dynamometer was aligned to the knee joint axis of rotation. In seated position, hip joint angle was 
adjusted at $90^{\circ}$ of knee joint flexion. Range of motion was 0 to $90^{\circ}$. Full extension was considered as zero (figure 1). In the lying position, hip joint was held in full extension and range of motion was adjusted from $0^{\circ}$ to $110^{\circ}$ (figure 2 ).

After that, participants were asked to do three maximal and reciprocal flexion and extension movements (repetitive cycles that were started with flexion movement and ended to extension movement) eccentrically and concentrically for knee joint flexors and extensors with 15 seconds rest between every repetitions and two minutes rest between trials $(21,22)$. The resistance provided by the weight of the lower leg was recorded at $30^{\circ}$ of flexion for gravity correction.

Data were recorded HUMAC NORM Software [HUMAC 2009, v.9.7.1] and Microsoft Excel files were extracted for the subsequent analysis. Peak torque values were normalized to body weight. H/Q ratios and the ACO were calculated using equations below:

\section{Equation 1:}

Conventional H/Q ratio = knee flexor concentric peak torque/knee extensor concentric peak torque $\times 100$.

\section{Equation 2 (4, 28):}

Functional H/Q ratio = knee flexor eccentric peak torque/ knee extensor concentric peak torque $\times 100$

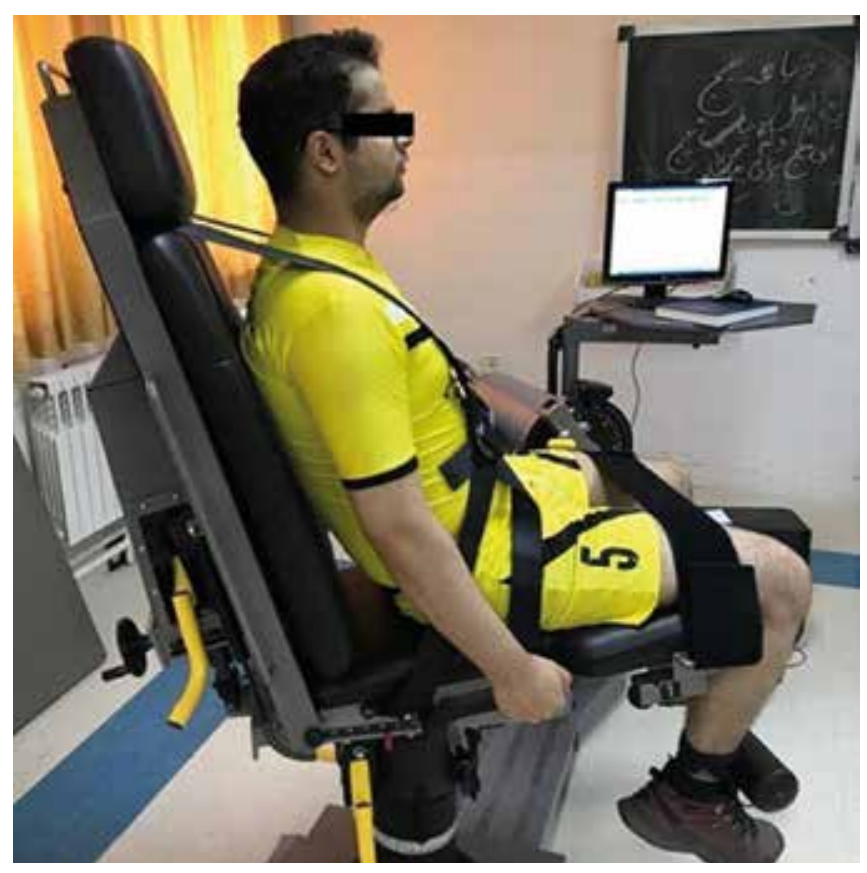

Figure 1. Isokinetic dynamometry of knee extensors and flexors was done in seated position.
Angle of cross over is an angle in which the difference between knee extensor concentric torque and knee flexor eccentric torque reaches zero (22).

$\mathrm{OL}$ as the angle that hamstrings demonstrate the eccentric peak torque in each testing position was also measured.

\section{Nordic hamstring test}

Subjects performed three repetitions of Nordic hamstring test on the mat. In a kneeling position, four LED markers attached to the lateral of hip, shoulder, knee joints and the lateral malleolus by an expert examiner. Subjects were instructed to keep shoulder, hip and knee joints in a straight line and were asked to try to keep this position steadily entire the movement. Ankles were stabilized by the examiner. Then, the subjects were instructed to do forward falling until they could no longer resist the gravity force and start to fall (figure 3). This Procedure (in three trials with two minutes rest between trials) was recorded by the Apple iPhone 7+ camera [Slo-mo video support for 720 pixels at 240 frames per second] at the rate of 240 frames per second at the distance of two-meters away from the subjects. The best of three repetitions (close to ground) was considered as the test trial and used for the further analysis. After the videos were recorded, data sent to the Kinovea Software. The validity and reliability of the Kinovea program [Beta 0.8.27] in obtaining angles and distances was studied in some studies recently (29). This program was detecting the LED markers on the video file and extract joints coordinates. Using coordinates, joint angle and speed diagrams

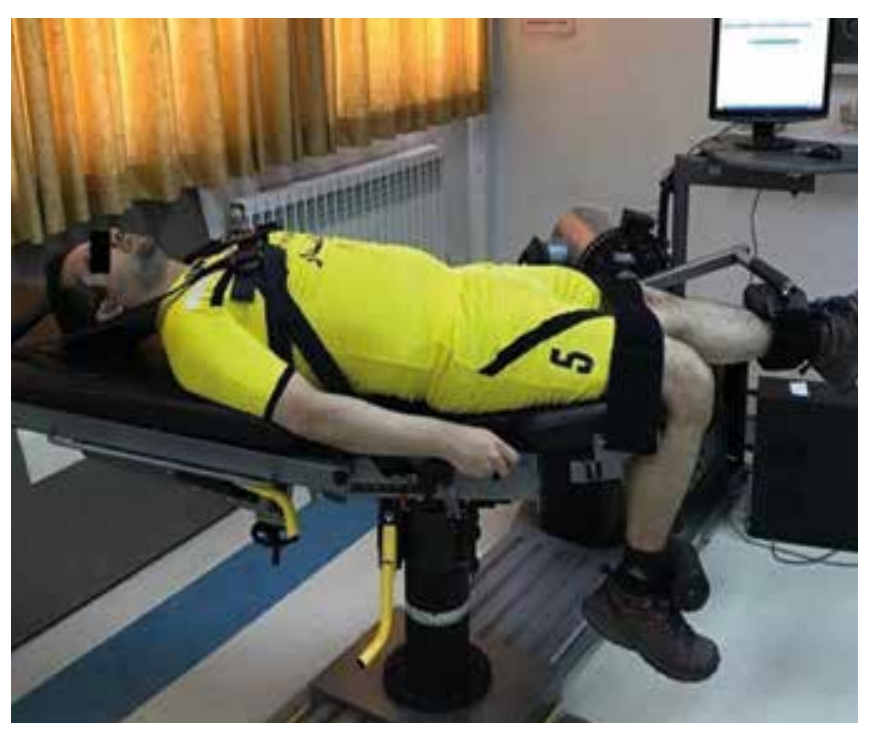

Figure 2. Isokinetic dynamometry of knee extensors and flexors was done in lying position. 

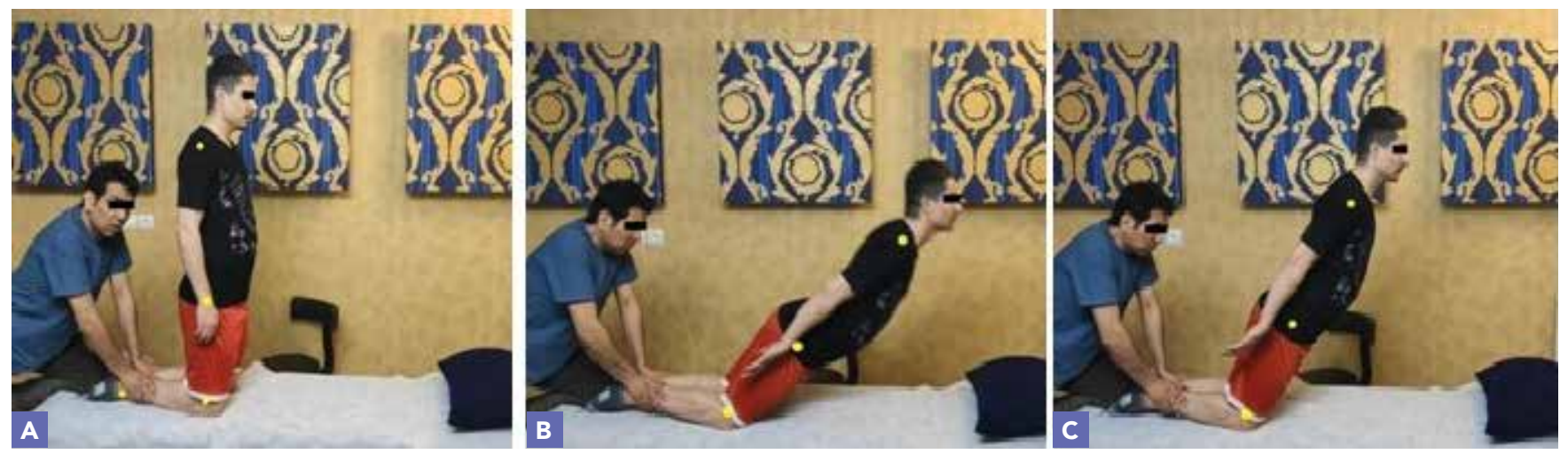

Figure 3. Nordic hamstring test was carried out using a camera. Figure a showing starting position and figure $b$ showing mid-pint position and $c$ the end position to indicate the break point angle. The break point angle is defined as the angle between the line passing the shoulder through the lateral aspect of the knee joint and the horizontal line when the subject cannot overcome the gravitational moment and falls to the floor.

were plotted. The point that speed was greater than $10 \%$ second was considered as the $\operatorname{BPA}(17,21,22)$.

\section{Statistical analysis}

Data collected from subjects were analyzed by SPSS version 13.0 [Statistical Package for Social Sciences, Chicago, IL]. Normality of the data was confirmed by Shapiro-Wilk test. The ICC values were interpreted according to the Landis and Koch criteria (0-0.02 as poor, 0.21-0.40 as fair, 0.410.6 as moderate, $0.71-0.80$ as substantial and $0.81-1$ as almost perfect (30)). Correlation between BPA and isokinetic dynamometry indices was calculated using Bivariate Pearson product-moment correlation coefficient $(\mathrm{r})$. The magnitudes of these correlations were considered as negligible (0.0-0.1), small (0.1-0.3), moderate (0.3-0.5), large (0.5$0.7)$, very large (0.7-0.9), or extremely large (0.9-1.0). Linear regression was also conducted to explore the relationships between isokinetic dynamometry indicesand BPA. $\mathrm{P}<0.05$ was assumed as significant level $(31,32)$.

\section{RESULTS}

Demographic variables and descriptive statistics for isokinetic dynamometry indices and BPA are presented in table I. Two groups of athletes were matched based on the demographic variables (table I). The results of test-retest analysis show that all variables have almost perfect reliability (table II).

There were strong correlations between isokinetic dynamometry indices (hamstring eccentric peak torques and $\mathrm{ACO})$ and Nordic break point angle in football $(\mathrm{P}=0.000)$.
In track and field, the correlation between isokinetic dynamometry indices (hamstring eccentric peak torque and $\mathrm{ACO}$ ) and Nordic break point angle was also observed ( $\mathrm{P}=$ 0.000). The amounts of Pearson product-moment correlation coefficient $(r)$ were higher in the lying position of dynamometry compared to the seated position. The results of correlation between isokinetic dynamometry indices and $\mathrm{BPA}$ are presented in table III.

Based on the regression analysis, dynamometry indices in lying position including knee flexor eccentric peak torque, $\mathrm{ACO}$, and $\mathrm{H} / \mathrm{Qs}$ were predictors of BPA in football. In track and field, only two indices including ACO and conventional H/Q were related to the BPA (table III).

\section{DISCUSSION}

The results revealed that in both groups, the correlations between BPA and hamstring eccentric peak torque and ACO were very strong. The amounts of correlation were higher in the lying position compared to the seated position. There were moderate correlations between the OL and BPA in two groups although higher correlations were obtained for lying position. These results may be revealing that the NHT as a field test is related to the isokinetic dynamometry as a laboratory gold standard test. Therefore, the Nordic hamstring test can be applied as an alternate screening tool to evaluate athletic performance. Although, there were no correlations between $\mathrm{H} / \mathrm{Q}$ ratios and $\mathrm{BPA}$, the conventional $\mathrm{H} / \mathrm{Q}$ ratios have predicted BPA. Other predictors of BPA were as follows: hamstring eccentric peak torque, and ACO respectively in football, and ACO in track and field. It means that muscle balance ratios are important laboratory 
Table I. Mean \pm SD for demographic variables and descriptive for isokinetic dynamometry indices and Nordic hamstring test index (break point angle).

\begin{tabular}{llll}
\hline Variable & Football $(\mathbf{N}=22)$ & Track and field $(\mathbf{N}=22)$ & P-value \\
\hline Age $($ years $)$ & $21.41 \pm 1.86$ & $21.55 \pm 1.62$ & 0.797 \\
\hline Body weight $(\mathrm{Kg})$ & $69.32 \pm 9.70$ & $65.21 \pm 10.51$ & 0.503 \\
\hline Height $($ meter$)$ & $1.79 \pm 0.09$ & $1.77 \pm 0.10$ & 0.185 \\
\hline Body mass index $(\mathrm{Kg} / \mathrm{m} 2)$ & $21.53 \pm 1.04$ & $20.67 \pm 1.10$ & 0.112 \\
\hline Seated Knee-flexor eccentric peak torque $(\mathrm{Nm})$ & $118.93 \pm 26.43$ & $131.88 \pm 32.08$ & 0.151 \\
\hline Lying knee-flexor eccentric peak torque $(\mathrm{Nm})$ & $99.09 \pm 17.92$ & $99.79 \pm 29.16$ & 0.924 \\
\hline Seated angle of Crossover $\left(^{\circ}\right)$ & $33.27 \pm 3.81$ & $34.73 \pm 5.36$ & \\
\hline Lying angle of Crossover $\left(^{\circ}\right)$ & $30.09 \pm 3.39$ & $32.35 \pm 4.48$ & \\
\hline Seated Knee-flexor eccentric optimum length $\left(^{\circ}\right)$ & $41.04 \pm 6.56$ & $37.96 \pm 7.22$ & \\
\hline Lying Knee-flexor eccentric optimum length $\left(^{\circ}\right)$ & $47.15 \pm 5.40$ & $46.06 \pm 5.31$ & \\
\hline Seated conventional hamstring to quadriceps ratio & $0.68 \pm 5.19$ & $0.68 \pm 6.00$ & 0.146 \\
\hline Lying conventional hamstring to quadriceps ratio & $0.63 \pm 6.78$ & $0.61 \pm 6.70$ & 0.504 \\
\hline Seated functional hamstring to quadriceps ratio & $0.77 \pm 6.17$ & $0.76 \pm 5.31$ & 0.730 \\
\hline Lying functional hamstring to quadriceps ratio & $0.76 \pm 5.94$ & $0.75 \pm 4.98$ & \\
\hline Nordic break point angle $\left(^{\circ}\right)$ & $41.67 \pm 3.47$ & $38.04 \pm 5.39$ & 0.404 \\
\hline
\end{tabular}

*P-value less than 0.05 was considered as significant

Table II. Test-retest analysis.

\begin{tabular}{|c|c|c|}
\hline Variable & Football ICC $(1,3) 95 \% \mathrm{CI}^{\mathrm{a}}$ & Track and field ICC $(1,3) 95 \%$ CI \\
\hline Seated Knee-flexor eccentric peak torque $(\mathrm{Nm})$ & $0.990(0.9750 .996)$ & $0.997(0.993-0.999)$ \\
\hline Lying knee-flexor eccentric peak torque $(\mathrm{Nm})$ & $0.984(0.9610 .993)$ & $0.994(0.9880 .998)$ \\
\hline Optimum length (Lying) $\left(^{\circ}\right)$ & $0.977(0.9450 .990)$ & $0.973(0.9360 .989)$ \\
\hline Angle of crossover (Seated) $\left(^{\circ}\right)$ & $0.983(0.9610 .993)$ & $0.986(0.9670 .994)$ \\
\hline Lying conventional H/Q & $0.929(0.8280 .970)$ & $0.934(0.8420 .973)$ \\
\hline Seated functional H/Q & $0.899(0.7570 .958)$ & $0.890(0.7360 .954)$ \\
\hline Lying functional H/Q & $0.931(0.8340 .971)$ & $0.831(0.5930 .930)$ \\
\hline Nordic break point angle $\left(^{\circ}\right)$ & $0.931(0.8420 .971)$ & $0.981(0.9550 .992)$ \\
\hline
\end{tabular}

indices to predict athletic performance on field. The results of reliability analysis also reveal that isokinetic dynamometry and NHT indices have almost perfect reliability which is in agreement with previous reports (17).

Although isokinetic dynamometry is introduced as a golden standard test for muscle strength assessment (33), as mentioned earlier, it has various practical limitations. Therefore, it is recommended in the previous literature to use more functional and easily applicable tests on field for athletes $(21,34)$. The results of this study support the findings of the previous studies with regard to $\operatorname{NHT}(17,21,22)$. The strong correlation between eccentric hamstring peak torque and BPA indicates that NHT can be used as a field test to demonstrate eccentric hamstring capabilities in football $(17,21,22)$. Generally, in the present study the amounts of correlation between eccentric hamstrings peak torques and BPA in football were higher compared to other reports in this area $(17,21,22)$. Differences in physical activity level 
Table III. Correlations between isokinetic dynamometry indices and Nordic Break point angle.

\begin{tabular}{lll}
\hline Variable & Football $(\mathbf{N}=\mathbf{2 2})$ & Track and field $(\mathbf{N}=\mathbf{2 2})$ \\
\hline Seated Knee-flexor eccentric peak torque $(\mathrm{Nm})$ & $(\mathrm{r}=-0.816, \mathrm{P}<0.001)^{*}$ & $(\mathrm{r}=-0.795, \mathrm{P}<0.001)^{*}$ \\
\hline Lying knee-flexor eccentric peak torque $(\mathrm{Nm})$ & $(\mathrm{r}=-0.860, \mathrm{P}<0.001)^{*}$ & $(\mathrm{r}=-0.816, \mathrm{P}<0.001)^{*}$ \\
\hline Seated $\mathrm{ACO}\left(^{\circ}\right)$ & $(\mathrm{r}=-0.797, \mathrm{P}<0.001)^{*}$ & $(\mathrm{r}=-0.877, \mathrm{P}<0.001)^{*}$ \\
\hline Lying ACO $\left(^{\circ}\right)$ & $(\mathrm{r}=-0.817, \mathrm{P}<0.001)^{*}$ & $(\mathrm{r}=-0.902, \mathrm{P}<0.001)^{*}$ \\
\hline Seated OL $\left.{ }^{\circ}\right)$ & $(\mathrm{r}=0.448, \mathrm{P}=0.037)^{*}$ & $(\mathrm{r}=0.466, \mathrm{P}=0.029)^{*}$ \\
\hline Lying OL $\left(^{\circ}\right)$ & $(\mathrm{r}=0.499, \mathrm{P}=0.018)^{*}$ & $(\mathrm{r}=0.486, \mathrm{P}=0.022)^{*}$ \\
\hline Seated conventional H/Q & $(\mathrm{r}=-0.194, \mathrm{P}=0.386)$ & $(\mathrm{r}=-0.258, \mathrm{P}=0.247)$ \\
\hline Lying conventional H/Q & $(\mathrm{r}=-0.411, \mathrm{P}=0.058)$ & $(\mathrm{r}=-0.496, \mathrm{P}=0.019)^{*}$ \\
\hline Seated functional H/Q & $(\mathrm{r}=-0.304, \mathrm{P}=0.170)$ & $(\mathrm{r}=-0.183, \mathrm{P}=0.414)$ \\
\hline Lying functional H/Q & $(\mathrm{r}=0.010, \mathrm{P}=0.964)$ & $(\mathrm{r}=-0.275, \mathrm{P}=0.215)$ \\
\hline
\end{tabular}

* Denotes significant.

${ }^{a}$ Knee-flexor eccentric Optimum length.

${ }^{\mathrm{b}}$ Hamstring to Quadriceps Ratio.

Table IV. The results of regression analysis to explore the relationships between isokinetic dynamometry indices and Nordic Break point angle.

\begin{tabular}{|c|c|c|}
\hline Variable & Football $(\mathrm{N}=22)$ & Track and field $(\mathrm{N}=22)$ \\
\hline Seated Knee-flexor eccentric peak torque $(\mathrm{Nm})$ & $($ Beta $=-0.010, P=0.979)$ & $($ Beta $=-0.316, \mathrm{P}=0.309)$ \\
\hline Lying knee-flexor eccentric peak torque $(\mathrm{Nm})$ & $(\text { Beta }=-0.851, \mathrm{P}=0.031)^{*}$ & $($ Beta $=-0.529, P=0.97)$ \\
\hline Lying ACO $\left(^{\circ}\right)$ & $(\text { Beta }=-0.498, P=0.021)^{*}$ & $(\text { Beta }=-0.742, \mathrm{P}=0.038)^{*}$ \\
\hline Seated $\mathrm{OL}^{\mathrm{b}}\left(^{\circ}\right)$ & $($ Beta $=0.177, \mathrm{P}=0.547)$ & $($ Beta $=0.260, P=0.326)$ \\
\hline Lying conventional H/Q & $(\text { Beta }=-1.02, \mathrm{P}=0.002)^{*}$ & $(\text { Beta }=-0.901, P=0.031)^{*}$ \\
\hline Seated functional H/Q & $($ Beta $=-0.285, P=0.352)$ & $($ Beta $=0.134, P=0.718)$ \\
\hline Lying functional H/Q & $(\text { Beta }=-0.946, P=0.004)^{*}$ & $($ Beta $=0.506, P=0.195)$ \\
\hline
\end{tabular}

* Denotes significant.

a Angle of cross over.

${ }^{\mathrm{b}}$ Knee flexor eccentric optimum length.

${ }^{c}$ Hamstring to Quadriceps ratio.

of athletes included in the studies may explain this discrepancy to some extent $(17,21)$. In the present study student athletes were included based on the Tegner physical activity questionnaire score. In the study of sconce et al., the physical activity level of participating athletes was not clarified (21). In the study of Lee et al., semi-professional athletes were participated (22) and in another study by Lee et, al, professional football players were selected (17). It is worth noting that the physical activity level is one of the factors attributable to the HS risk in athletes (6) and previous literature claimed that the level of athletic performance could affect the results of dynamometry (35). Therefore, it is not possible to generalize the results of NHT without considering the skill and physical activity level of athletes. Also, the time interval between dynamometry and NHT in the Lee study was about 7 to 10 days (22). Accordingly, methodological differences may also account to obtain different relationships.

As mentioned earlier, NHT characteristics were only surveyed in football $(17,21,22)$. Thus, the applicability of NHT for other sports remains questionable. Since the HS is defined as the most common muscle injury in track and field athletes (36), we assessed the relationship between NHT and isokinetic dynamometry indices in both football and 
track and field. Interestingly, the strong correlation between eccentric hamstring peak torque and NHT was seen in track and field. It means NHT can also be used to assess athletic performance in track and field. Of course, the present study is the first study that reports the results of NHT in track and field sport. More studies are warranted in this area.

Eccentric hamstring peak torque is categorized as one of the most important risk factors for the HS $(5,6,37-39)$. ACO as an indicator of knee joint muscle balance is another isokinetic dynamometry index that was also considered to assess the HS risk among athletes $(4,12)$. In accordance to the other reports (21) the results of the present study demonstrated that there are strong relationships between ACO and NHT in both groups and in two test positions. Moreover, the relationship of eccentric hamstring peak torque and NHT was the largest in football while, the relationship of ACO and NHT was largest in track and field. These findings indicate that relationships between laboratory and on-field test to estimate athletic performance are sport specific. Therefore, these considerations should be taken into account when estimating athletic performance based on the laboratory measures. Although, the role of H/Q ratios to predict HS is remaining controversial $(10,40)$. Lee, et al. reported that conventional $\mathrm{H} / \mathrm{Q}$ ratio obtained below $50.5 \%$ increases the HS risk to almost threefold in soccer (37). However, Bennell showed that these ratios were unable to predict the HS in Australian football (41). As mentioned before, in the current study there are almost no correlations between $\mathrm{H} / \mathrm{Q}$ ratios and NHT in both groups. However, regression analysis showed that best predictors of BPA in football were lying conventional H/Q ratio, hamstring eccentric peak torque, and lying ACO respectively and also best predictors of BPA in track and field were lying conventional H/Q ratio and lying ACO. Altogether, muscle balance indices seem to be an important index alongside the other laboratory measures. These indices possibly can explore different aspects of hamstring muscle eccentric performance in various sports. A moderate correlation between OL and BPA was found in the current study which is similar to the findings of Sconce study (21).

Commonly the relationship between seated isokinetic dynamometry indices and NHT were determined (17, 21,
22). The hamstring muscle is a bi-articular muscle. Therefore, the hip joint position affects the amount of torque produced by hamstrings. Previous studies revealed that the hamstrings'eccentric peak torque was higher in more flexed hip joint angles $(24,25,42)$. NHT is designated to evaluate the hamstring eccentric capability while maintaining hip joint in nearly extended position $(17,21,22)$. Therefore, knee joint dynamometry in hip extension is better resembling the athletic performance. The correlations between isokinetic dynamometry obtained in the lying position and BPA indices were higher compared to dynamometry in the seated position. Furthermore, only isokinetic indices obtained in the lying position could predict the NHT results. Finally, it is recommended to consider the role of mono-and bi-articular muscles when estimating athletic performance based on the laboratory results.

Our study has some limitations. Side to side difference is not achievable by the results of NHT. It is recommended to assess the amounts of hamstring muscle activity level and onset latencies with respect to the BPA in the future studies. Only male athletes were allocated in this study. Since, HS may occur in other sports such as rugby and Australian football; we suggest NHT survey with respect to sport type, activity level and playing position in different playing seasons.

Based on the results, Nordic hamstring test is correlated with isokinetic dynamometry as a gold standard. Therefore, NHT can be used on field to explore the athletic performance in football and track and field. Muscle balance about knee joint is also an important issue considering hamstring injury risk factors in football and track and field. When using isokinetic devices, the dynamometry position should be taken into account.

\section{ACKNOWLEDGEMENTS}

The authors would like to thank the Tabriz University of Medical Sciences that supported the project and athletes who participated in this study.

\section{CONFLICT OF INTERESTS}

The authors declare that they have no conflict of interests.

\section{REFERENCES}

1. Hickey J, Shield AJ, Williams MD, Opar DA. The financial cost of hamstring strain injuries in the Australian Football League. Br J Sports Med 2014;48(8):729-30.

2. Prior M, Guerin M, Grimmer K. An evidence-based approach to hamstring strain injury: a systematic review of the literature. Sports health 2009;1(2):154-64.
3. Drezner J, Ulager J, Sennett M. Hamstring muscle injuries in track and field athletes: a 3-year study at the Penn Relay Carnival. Clin J Sport Med 2005;15(5):386.

4. Coombs R, Garbutt G. Developments in the use of the hamstring/quadriceps ratio for the assessment of muscle balance. J Sports Sci Med 2002;1(3):56. 
5. Yeung SS, Suen AM, Yeung EW. A prospective cohort study of hamstring injuries in competitive sprinters: preseason muscle imbalance as a possible risk factor. Br J Sports Med 2009;43(8):589-94.

6. Askling C, Karlsson J, Thorstensson A. Hamstring injury occurrence in elite soccer players after preseason strength training with eccentric overload. Scand J Med Sci Sports 2003;13(4):244-50.

7. Fouasson-Chailloux A, Menu P, Mesland O, Guillodo Y, Crenn V, Dauty M. Evolution of isokinetic strength and return to sport after proximal hamstring rupture without surgical repair: a retrospective series of cases. MLTJ 2019;9(2):173-80.

8. de Paula Lima PO, Camelo PRP, Ferreira VMLM, et al. Evaluation of the isokinetic muscle function, postural control and plantar pressure distribution in capoeira players: a cross-sectional study. MLTJ 2017;7(3):498.

9. Grygorowicz M, Michałowska M, Walczak T, et al. Discussion about different cut-off values of conventional hamstring-to-quadriceps ratio used in hamstring injury prediction among professional male football players. PloS one 2017;12(12):e0188974.

10. Dauty M, Menu P, Fouasson-Chailloux A, Ferréol S, Dubois C. Prediction of hamstring injury in professional soccer players by isokinetic measurements. MLTJ 2016;6(1):116.

11. van Dyk N, Bahr R, Burnett AF, et al. A comprehensive strength testing protocol offers no clinical value in predicting risk of hamstring injury: a prospective cohort study of 413 professional football players. Br J Sports Med 2017;51(23):1695-702.

12. Graham-Smith P, Jones PA, Comfort P, Munro AG. Assessment of knee flexor and extensor muscle balance. Int J Athl Ther Trai 2013;18(5):1-5.

13. Wan X, Qu F, Garrett WE, Liu H, Yu B. Relationships among hamstring muscle optimal length and hamstring flexibility and strength. J Sport Health Sci 2017;6(3):275-82.

14. Chang YW, Su FC, Wu HW, An KN. Optimum length of muscle contraction. Clin Biomech (Bristol, Avon) 1999;14(8):537-42.

15. Brughelli M, Cronin J. Altering the length-tension relationship with eccentric exercise. Sports Med 2007;37(9):807-26.

16. Whiteley R, Jacobsen P, Prior S, Skazalski C, Otten R, Johnson A. Correlation of isokinetic and novel hand-held dynamometry measures of knee flexion and extension strength testing. J Sci Med Sport 2012;15(5):444-50.

17. Lee JW, Cai MJ, Yung PS, Chan KM. Reliability, validity, and sensitivity of a novel smartphone-based eccentric hamstring strength test in professional football players. Int J Sports Physiol Perform 2018;13(5):620-4.

18. Brockett CL, Morgan DL, Proske U. Human hamstring muscles adapt to eccentric exercise by changing optimum length. Med Sci Sports Exerc 2001;33(5):783-90.

19. van der Horst N, Smits DW, Petersen J, Goedhart EA, Backx FJ. The preventive effect of the nordic hamstring exercise on hamstring injuries in amateur soccer players: a randomized controlled trial. Am J Sports Med 2015;43(6):1316-23.

20. Al Attar WSA, Soomro N, Sinclair PJ, Pappas E, Sanders $\mathrm{RH}$. Effect of injury prevention programs that include the Nordic hamstring exercise on hamstring injury rates in soccer players: a systematic review and meta-analysis. Sports Med 2017;47(5):907-16.

21. Sconce E, Jones P, Turner E, Comfort P, Graham-Smith P. The validity of the Nordic hamstring lower for a field-based assessment of eccentric hamstring strength. J Sport Rehabil 2015;24(1):13-20.

22. Lee JW, Li C, Yung PS, Chan K-M. The reliability and validity of a video-based method for assessing hamstring strength in football players. J Exerc Sci Fit 2017;15(1):18-21.

23. Ekstrand J, Hägglund M, Waldén M. Epidemiology of muscle injuries in professional football (soccer). Am J Sports Med 2011;39(6):1226-32.

24. Worrell TW, Perrin DH, Denegar CR. The influence of hip position on quadriceps and hamstring peak torque and reciprocal muscle group ratio values. J Orthop Sports Phys Ther 1989;11(3):104-7.

25. Guex K, Gojanovic B, Millet GP. Influence of hip-flexion angle on hamstrings isokinetic activity in sprinters. J Athl Train 2012;47(4):390-5.

26. Pekron CW. The Professional Student-Athlete: Undermining Amateurism as an Antitrust Defense in NCAA Compensation Challenges. Hamline L Rev 2000;24:24.

27. Padulo J, Oliva F, Frizziero A, Maffulli N. Basic principles and recommendations in clinical and field science research: 2018 update. MLTJ 2018;8(3):305-7.

28. Aagaard P, Simonsen EB, Trolle M, Bangsbo J, Klausen K. Isokinetic hamstring/quadriceps strength ratio: influence from joint angular velocity, gravity correction and contraction mode. Acta Physiol Scand 1995;154(4):421-7.

29. Puig-Diví A, Escalona-Marfil C, Padullés-Riu JM, Busquets A, Padullés-Chando X, Marcos-Ruiz D. Validity and reliability of the Kinovea program in obtaining angles and distances using coordinates in 4 perspectives. PloS one 2019;14(6):e0216448.

30. Hanfelt JJ. Statistical approaches to experimental design and data analysis of in vivo studies. Breast Cancer Res Treat 1997;46(2-3):279-302.

31. Vincent WJ, Weir JP. Statistics in Kinesiology. Des Moines University: Champaign, IL: Human Kinetics 2012.

32. Thomas JR, Nelson JK, Silverman SJ. Research methods in physical activity: Human Kinetics 2015.

33. Harding AT, Weeks BK, Horan SA, Little A, Watson SL, Beck BR. Validity and test-retest reliability of a novel simple back extensor muscle strength test. SAGE Open Med 2017;5:2050312116688842.

34. Opar DA, Piatkowski T, Williams MD, Shield AJ. A novel device using the Nordic hamstring exercise to assess eccentric knee flexor strength: a reliability and retrospective injury study. J Orthop Sports Phys Ther 2013;43(9):636-40.

35. Siqueira CM, Pelegrini FRMM, Fontana MF, Greve JMD. Isokinetic dynamometry of knee flexors and extensors: comparative study among non-athletes, jumper athletes and runner athletes. Rev Hosp Clin Fac Med Sao Paulo 2002;57(1):19-24.

36. Malliaropoulos N, Mendiguchia J, Pehlivanidis $\mathrm{H}$, et al. Hamstring exercises for track and field athletes: injury and exercise biomechanics, and possible implications for exercise selection and primary prevention. Br J Sports Med 2012;46(12):846-51.

37. Lee JW, Mok KM, Chan HC, Yung PS, Chan KM. Eccentric hamstring strength deficit and poor hamstring-to-quadriceps ratio are risk factors for hamstring strain injury in football: A prospective study of 146 professional players. J Sci Med Sport 2018;21(8):789-93. 
38. Heiderscheit BC, Sherry MA, Silder A, Chumanov ES, Thelen DG. Hamstring strain injuries: recommendations for diagnosis, rehabilitation, and injury prevention. J Orthop Sports Phys Ther 2010;40(2):67-81.

39. Sugiura Y, Saito T, Sakuraba K, Sakuma K, Suzuki E. Strength deficits identified with concentric action of the hip extensors and eccentric action of the hamstrings predispose to hamstring injury in elite sprinters. J Orthop Sports Phys Ther 2008;38(8):457-64.
40. Freckleton G, Pizzari T. Risk factors for hamstring muscle strain injury in sport: a systematic review and meta-analysis. $\mathrm{Br}$ J Sports Med 2013;47(6):351-8.

41. Bennell K, Wajswelner H, Lew P, et al. Isokinetic strength testing does not predict hamstring injury in Australian Rules footballers. Br J Sports Med 1998;32(4):309-14.

42. Kellis E, Galanis N, Kofotolis N, Hatzi A. Effects of hip flexion angle on surface electromyographic activity of the biceps femoris and semitendinosus during isokinetic knee flexion. MLTJ 2017;7(2):286 